\title{
Weapons-Grade MOX Fuel Burnup Characteristics in Advanced Test Reactor Irradiation
}

\section{Plutonium Futures - The Science 2006}

\author{
Gray S. Chang
}

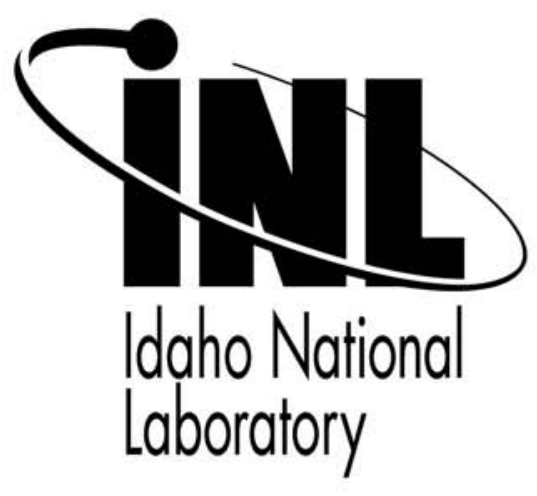

This is a preprint of a paper intended for publication in a journal or proceedings. Since changes may not be made before publication, this preprint should not be cited or reproduced without permission of the author. This document was prepared as an account of work sponsored by an agency of the United States Government. Neither the United States Government nor any agency thereof, or any of their employees, makes any warranty, expressed or implied, or assumes any legal liability or responsibility for any third party's use, or the results of such use, of any information, apparatus, product or process disclosed in this report, or represents that its use by such third party would not infringe privately owned rights. The views expressed in this paper are not necessarily those of the United States Government or the sponsoring agency. 
Ref. \# 3735706

\title{
Weapons-Grade MOX Fuel Burnup Characteristics in Advanced Test Reactor Irradiation
}

\author{
Gray S. Chang \\ Idaho National Laboratory \\ P. O. Box 1625 \\ Idaho Falls, ID 83415-3885 \\ e-mail: gray.chang@inl.gov
}

Correspondence should be sent to G. S. Chang at the above address, or Phone: 208-526-7646, Fax: 208-526-0528.

Title Page: 1, Abstract: 1, Text: 10, Figures: 3, Total pages: 15. 


\begin{abstract}
Mixed oxide (MOX) test capsules prepared with weapons-derived plutonium have been irradiated to a burnup of $50 \mathrm{GWd} / \mathrm{t}$. The MOX fuel was fabricated at Los Alamos National Laboratory (LANL) by a master-mix process and has been irradiated in the Advanced Test Reactor (ATR) at the Idaho National Laboratory (INL). Previous withdrawals of the same fuel have occurred at 9, 21, 30, 40, and $50 \mathrm{GWd} / \mathrm{t}$. Oak Ridge National Laboratory (ORNL) manages this test series for the Department of Energy's Fissile Materials Disposition Program (FMDP).
\end{abstract}

A UNIX BASH (Bourne Again SHell) script CMO has been written and validated at the Idaho National Laboratory (INL) to couple the Monte Carlo transport code MCNP with

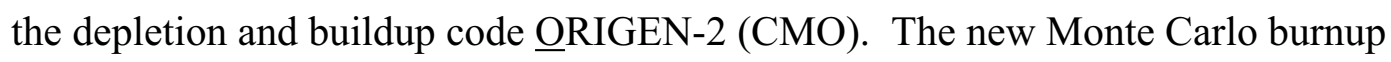
analysis methodology in this paper consists of $\underline{\mathrm{MCNP}}$ coupling through $\underline{\mathrm{CMO}} \underline{\text { with }}$ ORIGEN-2(MCWO). MCWO is a fully automated tool that links the Monte Carlo transport code MCNP with the radioactive decay and burnup code ORIGEN-2.

The fuel burnup analyses presented in this study were performed using MCWO. MCWO analysis yields time-dependent and neutron-spectrum-dependent minor actinide and $\mathrm{Pu}$ concentrations for the ATR small I-irradiation test position. The purpose of this report is to validate both the Weapons-Grade Mixed Oxide (WG-MOX) test assembly model and the new fuel burnup analysis methodology by comparing the computed results against the neutron monitor measurements and the irradiated WG-MOX post irradiation examination (PIE) data.

\title{
Key Words: Weapons-Grade Mixed Oxide Fuel MCNP MCWO ORIGEN2
}


Ref. \# 3735706

\section{INTRODUCTION}

The United States Department of Energy (DOE) Fissile Materials Disposition Program (FMDP) is pursuing methods of disposing surplus weapons-usable plutonium. One of the disposal methods being considered is irradiation of plutonium as a fissile constituent in Mixed Oxide (MOX) fuel for use by U.S. commercial light water reactors (LWR).

Given the last four decades of research, development, and deployment of MOX programs performed primarily in Europe, a large database of MOX fuel irradiation experience and knowledge already exists. Most of this experience and knowledge was gained using reactor-grade $(\mathrm{RG})$ plutonium, derived from spent low-enriched uranium fuel (LWR fuel). Irradiation testing conducted in the Advanced Test Reactor (ATR) at the Idaho National Laboratory (INL) supports the disposition mission by demonstrating that the introduction of WG plutonium does not compromise the applicability of the existing RGMOX database of experience and knowledge.

Since 1998, irradiation testing of WG-MOX fuel, prepared with WG plutonium (fabricated at Los Alamos National Laboratory (LANL) by a master-mix process), has been conducted in the ATR. One of the irradiation tests performed in the ATR was an experiment to support the potential licensing of MOX fuel for use in U S. LWRs. The uninstrumented test assembly included nine WG-MOX fuel capsules and neutron monitor wires. The irradiated test assembly achieved a burnup of $50 \mathrm{GWd} / \mathrm{t}$. 
Ref. \# 3735706

\section{MCWO METHOD}

The MCNP code [1] was developed by the X-6 division at LANL as a general-purpose Monte Carlo neutron transport simulation code. MCNP can model extremely complex 3-dimensional geometry, and is limited only by the computer memory capacity and time necessary to run such models to achieve the desired uncertainty band. MCNP uses continuous pointwise cross-section data evaluated from the ENDF/B-V library, and all neutron and photon reactions included in the library are accounted for by the MCNP calculations.

As computational power continues to increase, it becomes more practical to utilize Monte Carlo methods to perform burnup calculations. The UNIX Bourne Again SHell (BASH) script CMO developed at the INL, couples the Monte Carlo transport code $\underline{\text { MCNP with }}$ the depletion and buildup code ORIGEN-2 [2] (CMO). The Monte Carlo burnup analysis methodology used in this paper consists of $\underline{M C N P}$ coupling through $\underline{\mathrm{CMO}} \underline{\text { with }}$ ORIGEN-2 (MCWO $[3,4])$. The primary functions of MCNP are to calculate one-group cross-sections and fluxes (used by ORIGEN-2 in burnup calculations) and provide requested criticality and neutron economy information. After burnup calculations are performed by ORIGEN-2, CMO passes isotopic compositions of materials to MCNP to begin another burnup cycle. Applying this capability allows calculation of detailed nuclide concentration and power distributions within the MOX capsule as a function of burnup. 


\section{WG-MOX FUEL TEST ASSEMBLY MODEL}

The WG-MOX test fuel pellet is comprised of five percent $\mathrm{PuO}_{2}$ and $95 \%$ depleted $\mathrm{UO}_{2}$. The fuel capsule has a radius of $0.415 \mathrm{~cm}$ and a length of $15.24 \mathrm{~cm}$. Each of the nine fuel capsules contains fifteen MOX fuel pellets. The capsules in channel 1 are located the farthest away from the ATR core center. The capsules in channels 2 and 3 are closer to the ATR core center. Each axial section contains three fuel capsules, for a total of nine fuel capsules in one test assembly. The middle section is centered at the core midplane. All nine fuel capsules are included in the ATR MCNP Core Model. Three flux wire holders, each with Co and Ni wires are included in the WG-MOX fuel test assembly. Channel X contains the flux-wire closest to the ATR core center, and the flux wires in channels Y and Z are farthest from the ATR core center. The details are shown in Ref.3, Figure 2 .

\section{VALIDATION OF WG-MOX FUEL TEST ASSEMBLY MODEL}

The ability to accurately predict MOX fuel capsule power is essential to the WG-MOX fuel capsule design. The MCNP-calculated thermal and fast neutron fluxes were benchmarked against the measured Co-59 (thermal neutron flux) and Ni-58 (fast neutron flux) neutron monitor data.

The axial profile of the measured thermal and fast neutron fluxes along channel $\mathrm{Y}$ and the 
Ref. \# 3735706

MCNP-calculated flux average positions are shown in Figure 1. Figure 1 shows that the thermal neutron flux is depressed along the MOX fuel pin, due to the high thermal Pu fission cross-section, while the fast neutron flux peaks at the center of the MOX fuel pin. The averaged thermal neutron flux Calculated-to-Measured $(\mathrm{C} / \mathrm{M})$ ratios of channels $\mathrm{X}$, $\mathrm{Y}$, and $\mathrm{Z}$ are $1.05,1.08$, and 1.00, respectively. [5] For this experiment, these $\mathrm{C} / \mathrm{M}$ ratios demonstrate excellent agreement. Some of the smaller regions do not agree as well due to the statistical nature of Monte Carlo and the flux-wire counting.

\section{RESULTS AND DISCUSSION}

The experimental results of the Average Power Test (APT) include observations from the fuel fabrication process, PIE findings, $\mathrm{U}$ and $\mathrm{Pu}$ isotopic composition, and MOX fuel burnup. All of the capsules were visually examined in the transfer canal at the ATR during the shuffling and transfer to ORNL for PIE. All of the irradiated capsules appeared as fresh as they did at the original insertion. No changes in the external dimensions were noted. Oxidation of the external surfaces was likewise not noticeable. No appreciable scratches or wear spots were observed as might occur from fretting.

\subsection{Comparison of MCWO-calculated and ${ }^{148} \mathrm{Nd}$ Measured Burnup}

Fuel burnup is an important parameter needed for fuel performance evaluation. For the irradiated MOX fuel's PIE, the ${ }^{148} \mathrm{Nd}$ method [6] was used to measure the burnup with $1 \sigma \approx 5 \%$. MCNP calculated fission tally with $1 \sigma \approx 2.5 \%$. The initial experiment phase (Phase-I irradiation), which contained nine MOX fuel capsules, was loaded into the ATR 
Ref. \# 3735706

in January 1998. After 153.5 effective full power days (EFPDs) of irradiation in Phase-I, [7] a capsule pair was withdrawn from the ATR in September 1998. The MCWOcalculated average discharge burnup was $8.4 \mathrm{GWd} / \mathrm{t}$ compared to the ${ }^{148} \mathrm{Nd}$ measured burnup which was $7.96 \mathrm{GWd} / \mathrm{t}$.

At the end of Phase-II [8] irradiation (226.9 EFPDs), an additional capsule pair was withdrawn in September 1999 after having achieved a MCWO-calculated average discharge burnup of $21 \mathrm{GWd} / \mathrm{t}$, as compared to the ${ }^{148} \mathrm{Nd}$ measured burnup of 21.57 GWd/t. At the end of Phase-III [9] irradiation (232.8 EFPDs), an additional capsule pair was withdrawn in September 2000, after having achieved a MCWOcalculated average discharge burnup of $29.6 \mathrm{GWd} / \mathrm{t}$, as compared to the ${ }^{148} \mathrm{Nd}$ measured burnup of $29.86 \mathrm{GWd} / \mathrm{t}$. At the end of Phase-IV Part-1, capsules 4 and 13 were removed for PIE. [10] The MCWO-calculated average discharge burnup was $39.86 \mathrm{GWd} / \mathrm{t}$ compared to the ${ }^{148} \mathrm{Nd}$ measured burnup which was $40.44 \mathrm{GWd} / \mathrm{t}$.

In the final Phase-IV Part-2 of irradiation, capsules 6 and 12 were placed in the two front middle positions and capsule 5 in the front top position. At the end of the final irradiation cycle, Cycle 132C, the MCWO-calculated average discharge burnup was $50.45 \mathrm{GWd} / \mathrm{t}$, as compared to the ${ }^{148} \mathrm{Nd}$ measured burnup which was $50.6 \mathrm{GWd} / \mathrm{t}$. [11]

MCWO was used to track fuel burnup and heat rates as a function of irradiation time. In summary, the MCWO-calculated and ${ }^{148} \mathrm{Nd}$ measured burnup demonstrate good agreement . The MCWO-calculated depletion and build-up characteristics of ${ }^{239} \mathrm{Pu} / \mathrm{Pu}$ 
Ref. \# 3735706

and ${ }^{240} \mathrm{Pu} / \mathrm{Pu}$ versus burnup will be compared to PIE Mass Spectrometry (MS) measured data and discussed in the following section.

\subsection{MCWO-calculated Pu Burnup Characteristics versus MS Measured Data}

The MS method can be calibrated to achieve a highly accurate measurement by eliminating the mass discrimination bias. Mass ratio of Pu isotopes can be obtained by MS with $1 \sigma \approx 0.5 \%$, which can accurately validate MCWO method. The MCWOcalculated mass ratio profiles of ${ }^{239} \mathrm{Pu} / \mathrm{Pu}$ and ${ }^{240} \mathrm{Pu} / \mathrm{Pu}$ versus burnup are benchmarked with the MS measured data.

MCWO-calculated ratios of ${ }^{239} \mathrm{Pu} / \mathrm{Pu}$ versus burnup are shown in Figure 2. The initial ${ }^{239} \mathrm{Pu} / \mathrm{Pu}$ atom percent is $93.81 \%$. This decreases monotonically but not linearly with burnup. The MS measured ${ }^{239} \mathrm{Pu} / \mathrm{Pu}$ ratios and ${ }^{148} \mathrm{Nd}$ measured burnup have a good agreement with the MCWO-calculated curve of the ${ }^{239} \mathrm{Pu} / \mathrm{Pu}$ ratio as shown in Figure 3. The MCWO-calculated ${ }^{239} \mathrm{Pu} / \mathrm{Pu}$ ratio profile shows that the buildup of ${ }^{239} \mathrm{Pu}$ from ${ }^{238} \mathrm{U}$ is almost equivalent to the ${ }^{239} \mathrm{Pu}$ depletion when the ${ }^{239} \mathrm{Pu} / \mathrm{Pu}$ ratio reaches $20.6 \%$. MCWO-calculated ratios of ${ }^{240} \mathrm{Pu} / \mathrm{Pu}$ versus burnup are shown in Figure 3. The initial ${ }^{240} \mathrm{Pu} / \mathrm{Pu}$ atom percent is $5.9 \%$. This increases monotonically but not linearly with burnup. The MS measured ${ }^{240} \mathrm{Pu} / \mathrm{Pu}$ ratios and ${ }^{148} \mathrm{Nd}$ measured burnup have a good agreement with the MCWO-calculated curve of the ${ }^{240} \mathrm{Pu} / \mathrm{Pu}$ ratio as shown in Figure 3. One of the criteria in the definition of spent fuel standard, as defined by the National Academy of Sciences [12] is that the isotopic compositions of the discharged fuel should 
Ref. \# 3735706

be about the same as the light water reactor $\mathrm{UO}_{2}$ spent fuel, particularly, the ${ }^{240} \mathrm{Pu} / \mathrm{Pu}$ ratio should be greater than $24 \%$. The MCWO-calculated ${ }^{240} \mathrm{Pu} / \mathrm{Pu}$ ratio indicates that

${ }^{240} \mathrm{Pu} / \mathrm{Pu}$ for the WG-MOX fuel can reach $24 \%$ at the burnup of $17 \mathrm{GWd} / \mathrm{t}$. The ${ }^{240} \mathrm{Pu} / \mathrm{Pu}$ ratio reaches a peak value of $51 \%$ at $40 \mathrm{GWd} / \mathrm{t}$, then, decreases versus burnup.

\section{CONCLUSIONS}

The ability to accurately predict WG-MOX fuel pellet power profile, burnup, and isotope depletion profile is essential to evaluate the MOX fuel performance. Important neutronics parameters were computed using MCWO methods. This report utilizes the MCWO method to predict the needed neutronics parameters. The neutronics analyses include detailed radial fission and actinide reaction tallies in the fuel pins.

In this study, a detailed WG-MOX fuel test assembly model was developed. The model was validated by comparing the MCNP-calculated neutron fluxes with the flux-wire measurement data. There is excellent agreement between the MCNP-calculated results and the measured data. The validated WG-MOX fuel test assembly model was also used in the MCWO fuel burnup analyses, which provided the fuel burnup prediction during the irradiation Cycle 115C to Cycle 132C. 


\section{REFERENCES}

1. J. F. Briesmeister (Editor), "MCNP_A General Monte Carlo N-Particle Transport Code, Version 4C," LA-13709-M, Los Alamos National Laboratory (2000).

2. A. G. Croff, "ORIGEN2: A Versatile Computer Code for Calculating the Nuclide Compositions and Characteristics of Nuclear Materials," Nuclear Technology, Vol. 62, pp. 335-352, 1983.

3. G. S. Chang and J. M. Ryskamp, "Depletion Analysis of Mixed Oxide Fuel Pins in Light Water Reactors and the Advanced Test Reactor," Nucl. Technol., Vol. 129, No. 3, p. 326-337 (2000).

4. G. S. Chang, "MCWO - LINKING MCNP AND ORIGEN2 FOR FUEL BURNUP ANALYSIS,” Proceedings of “The Monte Carlo Method: Versatility Unbounded In A Dynamic Computing World, Chattanooga, Tennessee, April 1721, 2005, on CD-ROM, American Nuclear Society, LaGrange Park, IL (2005).

5. G. S. Chang, JW Rogers, and J. M. Ryskamp, "Neutron Flux and Spectrum Variation in a MOX Fuel Experiment,” Trans. Am. Nucl. Soc., Vol. 81, 284 (1999). 
Ref. \# 3735706

6. "Standard Test Method for Atom Percent Fission in Uranium and Plutonium Fuel (Neodymium-148 Method)", ASTM Standards, E-321-96.

7. R. N. Morris, C. A. Baldwin, B. S. Cowell, S. A. Hodge, et. al. "MOX Average Power Early PIE: 8 GWd/MT Final Report,” Oak Ridge National Laboratory, ORNL/MD/LTR-172, November 1999.

8. R.N. Morris, C. A. Baldwin, S. A. Hodge, L. J. Ott, C. M. Malone, N. H. Packan, "MOX Average Power Intermediate PIE: 21 GWd/MT Final Report," Oak Ridge National Laboratory, ORNL/MD/LTR-199, December 2000.

9. R.N. Morris, C. A. Baldwin, S. A. Hodge, N. H. PACKAN, "MOX Average Power 30 GWd/MT PIE: Final Report,” Oak Ridge National Laboratory, ORNL/MD/LTR-212, November 2001.

10. R. N. Morris, C. A. Baldwin, S. A. Hodge, N. H. Packan, "MOX Average Power 40 GWd/MT PIE: Final Report,” Oak Ridge National Laboratory, ORNL/MD/LTR-241, Volume 1, August 2003.

11. R. N. Morris, C. A. Baldwin, N. H. Packhan, "MOX Test Fuel 50 Wd/MT PIE: Capsules 6 and 12 Final Report," Oak Ridge National Laboratory, ORNL/MD/LTR-279, September, 2005. 
Ref. \# 3735706

12. National Academy of Sciences Committee on International Security and Arms, Management and Disposition of Excess Weapons Plutonium, National Academy Press, 1994. 
Ref. \# 3735706

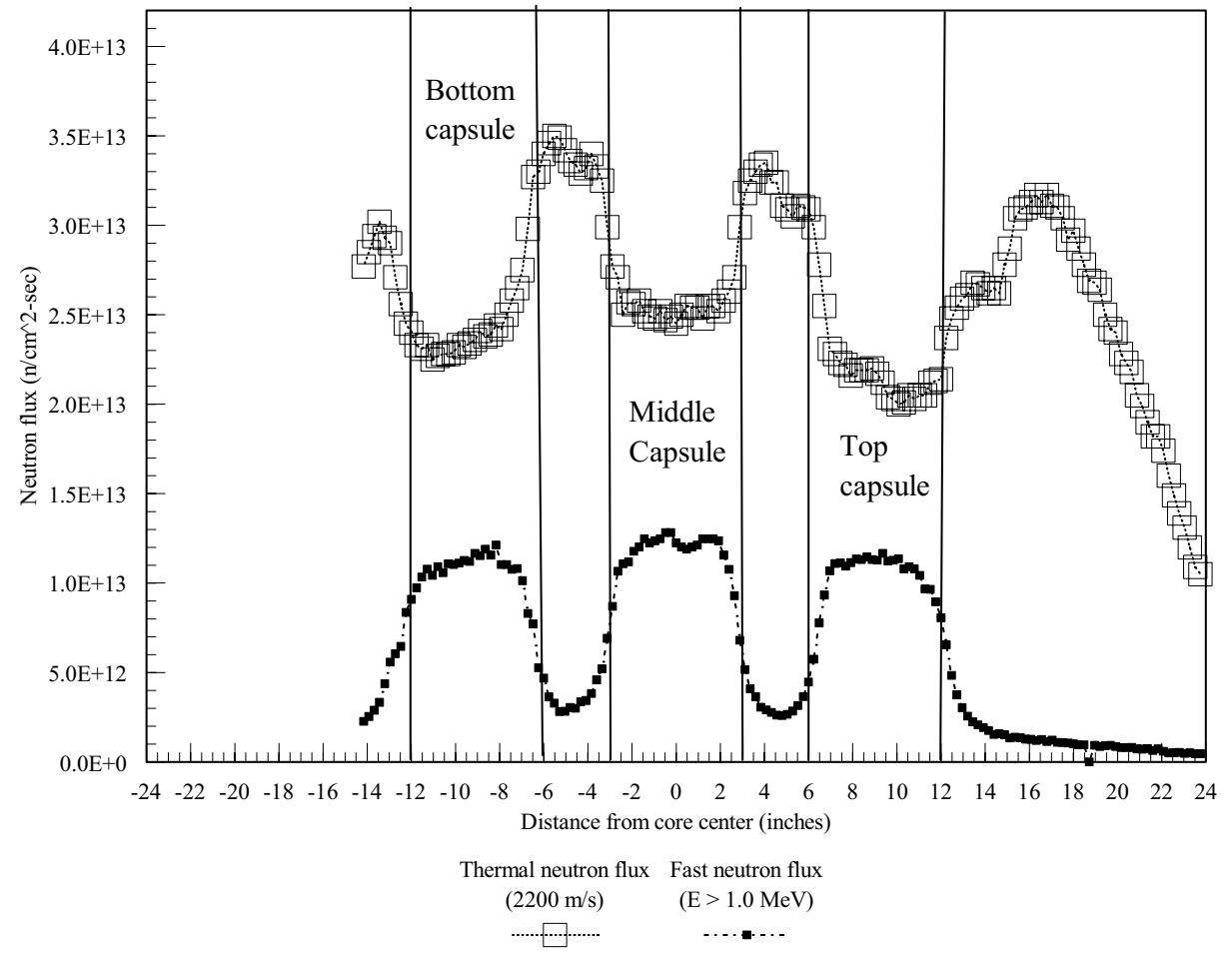

Figure 1. Measured channel Y thermal and fast neutron fluxes (ATR Cycle 115-C). 
Ref. \# 3735706

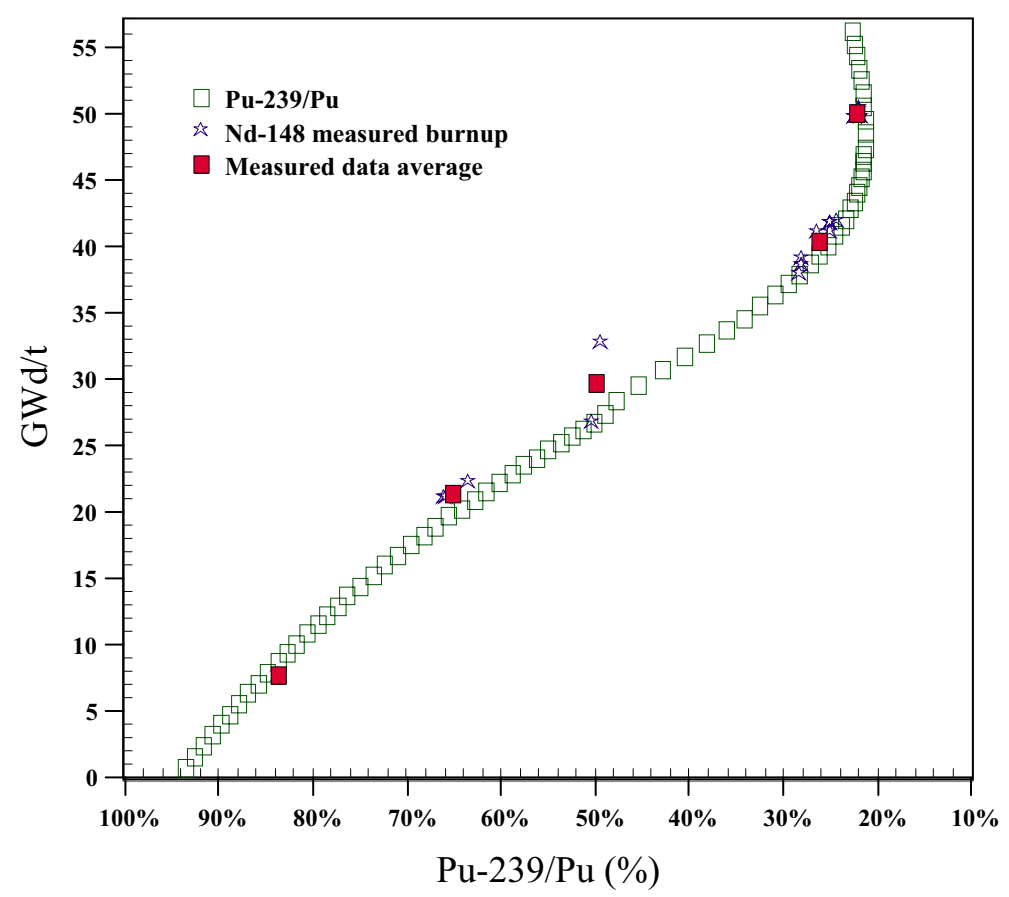

Figure 2: $\mathrm{MCWO}$-calculated ${ }^{239} \mathrm{Pu} / \mathrm{Pu}$ ratio profile and Mass-Spectrometer-measured data versus burnup. 
Ref. \# 3735706

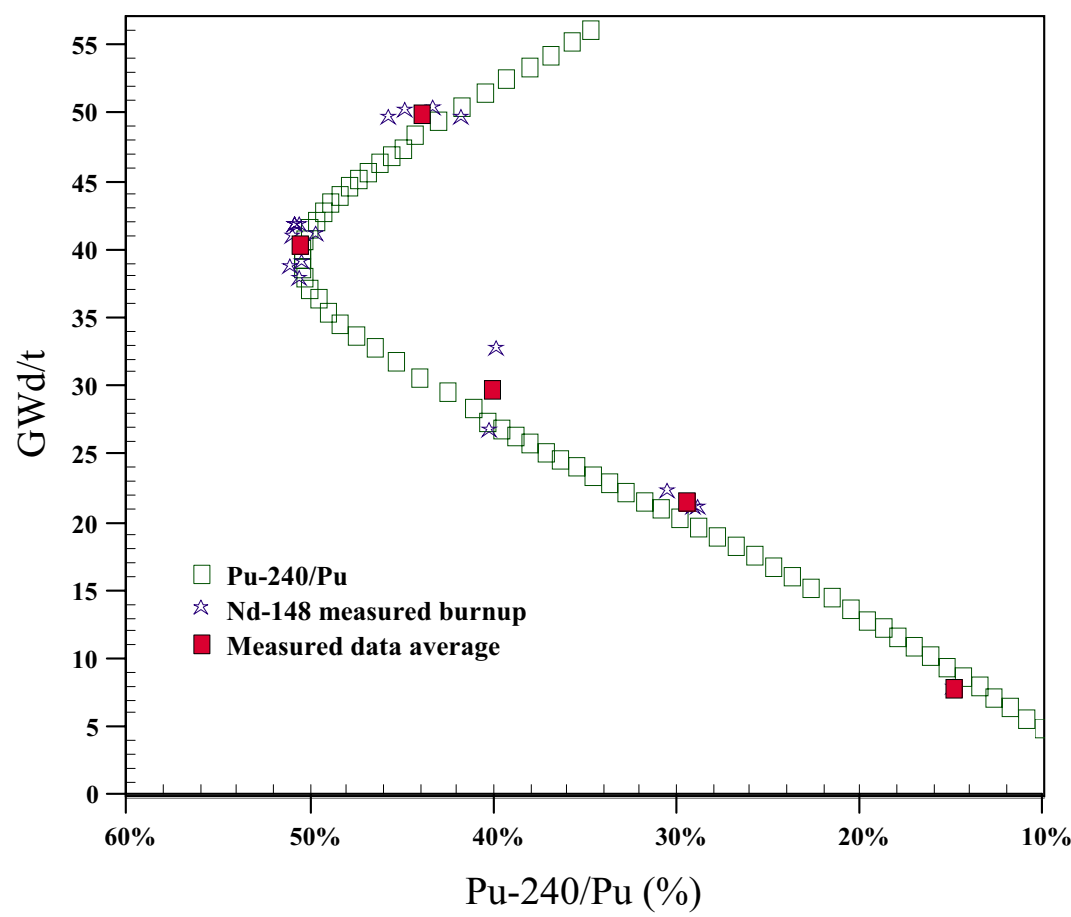

Figure 3: $\mathrm{MCWO}$-calculated ${ }^{240} \mathrm{Pu} / \mathrm{Pu}$ ratio profile and Mass-Spectrometer-measured data versus burnup. 